\title{
Prevalence and correlates of cognitive impairment and depression among elderly people in the world's fastest growing city, Chongqing, People's Republic of China
}

\author{
This article was published in the following Dove Press journal: \\ Clinical Interventions in Aging \\ 12 August 2016 \\ Number of times this article has been viewed
}

Mohan Giri, 1,* Tian Chen, 1,* Weihua Yu, ${ }^{2}$ Yang Lü'

'Department of Geriatrics, The First Affiliated Hospital of Chongqing Medical University, Yuzhong District, ${ }^{2}$ Institutes of Neuroscience, Chongqing Medical University, Chongqing, People's Republic of China

*These authors contributed equally to this work

Video abstract

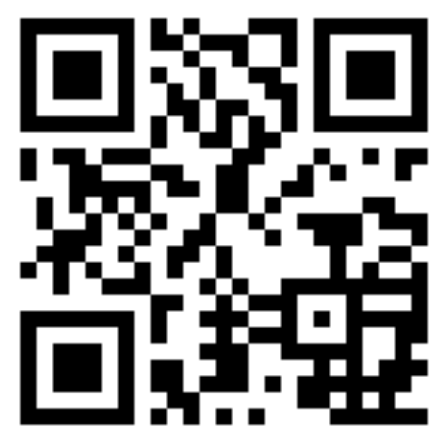

Point your SmartPhone at the code above. If you have a $Q R$ code reader the video abstract will appear. Or use: http://youtu.be/UYeY8nvt3rA

Correspondence: Yang Lü Department of Geriatrics, The First Affiliated Hospital of Chongqing Medical University, No I Youyi Road, Yuzhong District, Chongqing 400016, People's Republic of China

Tel +86 23 890I 1622

Fax +8623688I I487

Email lyu_yang@I26.com
Background: Cognitive impairment and depression are major mental health problems affecting older people. The current study was designed to explore the prevalence of cognitive impairment and depression in representative sample of elderly people aged $\geq 60$ years and to examine the correlates of cognitive impairment and depression with other sociodemographic variables.

Methods: A cross-sectional study based on comprehensive geriatric assessment of 538 elderly Chinese people was conducted from September 2011 to August 2012. Cognitive impairment was assessed using the Chinese version of Mini-Mental State Examination, and depressive symptoms were assessed by 30 -item geriatric depression scale.

Results: The prevalence of cognitive impairment was 12.6\%. Multiple logistic regression analysis revealed that the following were significant independent predictors of cognitive impairment: female, having a low level of education, increasing age, and depression. The overall prevalence of depression was $24.3 \%$, and in adjusted model, cognitive impairment was only associated with increased risk of depression.

Conclusion: Cognitive impairment and depression are prevalent in elderly Chinese people. Among a number of factors identified in our study, cognitive impairment and depression were highly correlated in elderly people aged $\geq 60$ years.

Keywords: cognitive impairment, depression, elderly Chinese, prevalence, risk factors

\section{Introduction}

Aging is an inevitable and complex process. The People's Republic of China has the largest elderly population in the world; currently, there are $\sim 160$ million people older than 60 years, and it is estimated that $\sim 30 \%$ of the total population in the People's Republic of China will be older than 60 years by $2050 .{ }^{1}$ In coming years, more elderly people will suffer from age-associated mental diseases. Depression is the most common psychiatric disorder found in the elderly people around the world. Late-life depression and cognitive impairment have become a global issue and exerted heavy burdens on the health care system and society. Late-life depression in elderly people may lead to physical illness, functional disability, and increased suicidal risk. The main risk factors associated with depression are older age, female sex, cognitive impairment, illiteracy, and fall in self-esteem. ${ }^{2-5}$ The magnitude of geriatric depression and cognitive impairment in the Chinese situation is a serious cause of concern.

Cognitive impairment and depression are often seen as comorbid conditions and major mental health problems affecting older people. ${ }^{2}$ The prevalence of depression cc) ${ }_{\mathrm{BY}} \mathrm{NC}$ and incorporate the Creative Commons Attribution - Non Commercial (unported, v3.0) License (http://creativecommons.org/licenses/by-n/3.0/). By accessing the work you hereby accept the Terms. Non-commercial uses of the work are permitted without any further permission from Dove Medical Press Limited, provided the work is properly attributed. For permission for commercial use of this work, please see paragraphs 4.2 and 5 of our Terms (https://www.dovepress.com/terms.php). 
varies widely in the different parts of the world, depending on social, cultural, and ethnic characteristics. The worldwide prevalence of late-life depression was estimated to range from $3 \%$ to $30 \%$ and depression may significantly affect the quality of life. ${ }^{3}$ Studies have revealed that in community-dwelling and institutionalized elderly people, the prevalence of depression was $9 \%$ and $25 \%$, respectively. ${ }^{4,5}$ Several studies showed that the prevalence rate of depression in elderly Chinese people ranged from $4 \%$ to $26.5 \% .{ }^{6-8}$ Clinicians often fail to diagnose and treat depression in elderly people.

The prevalence of cognitive impairments doubles every 5 years, affecting $20 \%$ of those aged 65 years and $45 \%$ of those aged $\geq 90$ years. ${ }^{9}$ Recent studies conducted in the People's Republic of China have shown that the prevalence of mild cognitive impairment for the people aged 60 years or older ranged from $3 \%$ to $36 \% .^{10-12}$ This wide variability may be due to types of study, different diagnostic criteria used, and age range used in the study.

The purpose of the present study was to 1) estimate the prevalence of late-life depression and cognitive impairment among elderly people older than 60 years in the world's fastest growing city, Chongqing and 2) examine the association of depression and cognitive impairment with sociodemographic characteristics of population.

\section{Methods}

\section{Location}

Chongqing is one of the five national central cities in the People's Republic of China and the largest municipality in Southwest China. There are 21 districts, 13 counties, and four autonomous counties in Chongqing. Chongqing has a geographical area of $82,403 \mathrm{~km}^{2}$ and population of 28.85 million in 2010 . Of the total population, $15 \%$ were elderly people (aged $>60$ years).

\section{Participants}

A cross-sectional study was conducted among elderly people aged 60 years and older who were recruited to finish comprehensive geriatric assessment (CGA) in the Department of Geriatrics, the First Affiliated Hospital of Chongqing Medical University and a Community Center of Jiangbei District, Chongqing, from September 2011 to August 2012. The study was approved by the institutional review board of Chongqing Medical University, and all the participants signed an informed consent.

Inclusion criteria comprised all consenting subjects aged 60 years and older. Exclusion criteria included people with communication difficulty due to hearing loss/dumb/blind and those with neurological or psychiatric disorders and dementia.

\section{Measures}

In a total of 538 eligible older adults (238 males and 300 females), CGA was conducted and data were collected by well-trained geriatricians via face-to-face interview at study site. CGA is a multidisciplinary diagnostic and treatment process that included demographic data, physical health and function assessment, evaluation of behavioral and social functioning, mental problems (cognitive deficit and depression), medical condition, functional components and instrumental activities of daily living, nutritional status assessment, and auxiliary examinations. Sociodemographic parameters included in our study were sex, age, marital status, monthly per capita income, and education.

\section{Depressive symptoms assessment}

Depressive symptoms were assessed by 30 -item geriatric depression scale (GDS-30). The GDS consists of 30-item assessment tool with scores ranging from 0 to 30 to identify geriatric depression. The score is obtained by summation of positive and negative responses. This scale was developed by Yesavage et $\mathrm{al}^{13}$ in 1982 and has been used to measure depression among elderly with high sensitivity (92\%-100\%) and specificity (84\%-87\%). GDS was validated in psychiatric outpatient sample of elderly Chinese people aged 60 years or older. ${ }^{14}$ The sensitivity and specificity were $70.6 \%$ and $70.1 \%$, respectively, and it is applicable to the elderly Chinese population and is good for measuring depressive symptoms. Individuals having a GDS score of 11 points or higher were considered to have significant depressive symptoms.

\section{Assessment of cognitive function}

Cognitive impairment was assessed using the Chinese version of Mini-Mental State Examination (MMSE). MMSE is widely used to screen cognitive function in the elderly people. ${ }^{15}$ It examines functions including language, registration, attention and calculation, recall, ability to follow simple commands, and orientation. Scores of MMSE range from 0 to 30, with higher scores indicating better cognitive function. Any score $\geq 24$ points indicates a normal cognition, and respondents with an MMSE score of $<24$ were regarded as cognitively impaired. Mild cognitive impairment was diagnosed using modified Petersen criteria. ${ }^{16}$

\section{Data analysis}

Statistical analyses were performed using the software package SPSS 20.0 (IBM Corporation, Armonk, NY, USA). Descriptive analysis was performed to evaluate the sociodemographic and other predictive factors. For continuous and categorical variables, mean (SD) and proportion 
were calculated, respectively. The prevalence of cognitive impairment and depression was calculated. Chi-square statistics was used to compare categorical variables. Factors associated with cognitive impairment and depression were initially investigated using univariate analysis. Multivariate analysis was followed, after adjustment of all variables included in univariate analysis. Odds ratio (OR), adjusted OR, and 95\% confidence interval (CI) were calculated to evaluate the association of depression and cognitive impairment with various factors. All the statistical tests reported here were two sided, and $P<0.05$ was considered as statistically significant.

\section{Results}

\section{Characteristics of study participants}

Of the 550 eligible older people who underwent CGA, 538 respondents had complete data and satisfied the inclusion criteria, giving a response rate of $97.8 \%$. Table 1 shows characteristics of the study sample. Participants ranged in age from 60 years to 94 years (with mean age of $72.58 \pm 7.71$ years). The mean MMSE score was 27.78 \pm 3.44 (Figure 1). There were more elderly females (55.8\%) than elderly males (44.2\%). The average age of males and females was essentially the same $(P=0.19)$. Females $(36.3 \%)$ were more likely to be single/divorced/widowed than males (14.3\%). More females were illiterate $(7.3 \%)$ than males $(2.1 \%)$. More than half of the participants $(59.5 \%)$ had an average monthly income of $<3,000$ yuan. Significant differences have been observed in the marital status, monthly income, and education of females and males (Table 1).

Table I Sociodemographic characteristics of the study population by sex $(\mathrm{N}=538)$

\begin{tabular}{|c|c|c|c|c|}
\hline Variables & $\begin{array}{l}\text { Male, } \\
\text { n (\%) }\end{array}$ & $\begin{array}{l}\text { Female, } \\
\text { n (\%) }\end{array}$ & $\begin{array}{l}\text { Total, } \\
\text { n (\%) }\end{array}$ & $P$-value \\
\hline Sex & $238(44.2)$ & $300(55.8)$ & $538(100.0)$ & \\
\hline Age (years) & & & & 0.187 \\
\hline $60-64$ & $45(19.0)$ & $62(20.7)$ & 107 (19.9) & \\
\hline $65-74$ & 91 (38.2) & $122(40.7)$ & $213(39.6)$ & \\
\hline $75-84$ & $81(34.0)$ & $105(35.0)$ & $186(34.6)$ & \\
\hline$\geq 85$ & $21(8.8)$ & II (3.6) & $32(5.9)$ & \\
\hline Marital status & & & & $<0.001$ \\
\hline Single/widow/divorce & $34(14.3)$ & $109(36.3)$ & I43 (26.6) & \\
\hline Married & 204 (85.7) & I91 (63.7) & 395 (73.4) & \\
\hline Monthly income (RMB) & & & & $<0.001$ \\
\hline$<3,000$ & $105(44.1)$ & 215 (7I.7) & $320(59.5)$ & \\
\hline $3,000-9,999$ & $130(54.6)$ & $83(27.7)$ & $213(39.6)$ & \\
\hline$\geq 10,000$ & $3(1.3)$ & $2(0.6)$ & $5(0.9)$ & \\
\hline Education (years) & & & & $<0.001$ \\
\hline 0 & $5(2.1)$ & $22(7.3)$ & $27(5.0)$ & \\
\hline $\mathrm{I}-5$ & $27(\mid \mathrm{I} .3)$ & $56(18.7)$ & $83(15.4)$ & \\
\hline $6-10$ & $67(28.2)$ & $84(28.0)$ & I5I (28.I) & \\
\hline$\geq I I$ & $139(58.4)$ & $138(46.0)$ & 277 (5।.5) & \\
\hline
\end{tabular}

Abbreviation: RMB, Renminbi.

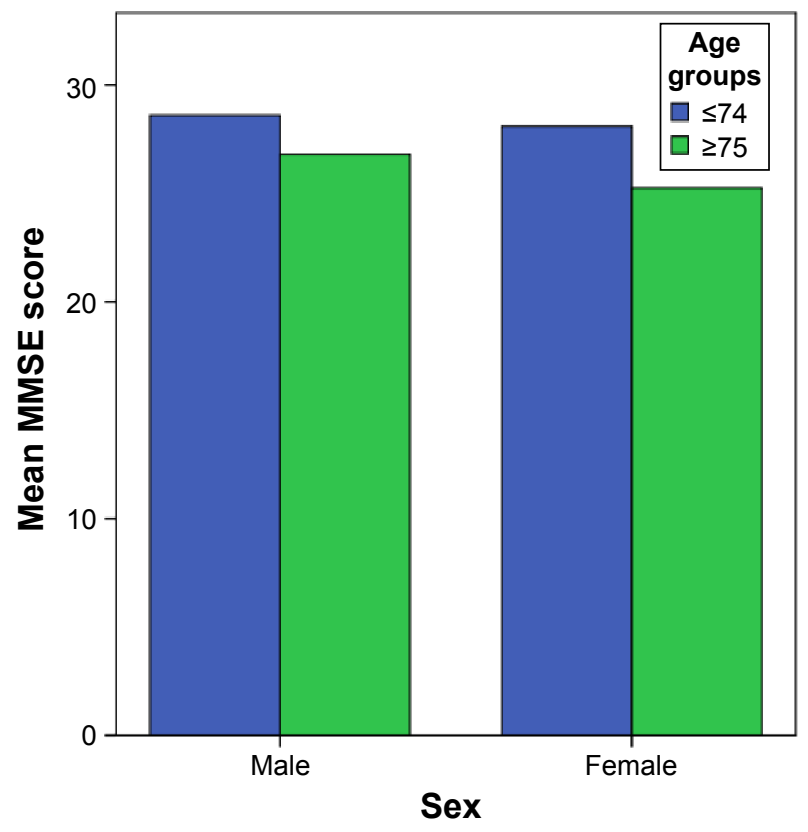

Figure I Sex-specific mean MMSE score for age groups. Abbreviation: MMSE, Mini-Mental State Examination.

\section{Prevalence of cognitive impairment and depression}

The prevalence rates for cognitive impairment and depression are shown in Table 2. The overall prevalence of cognitive impairment was 12.6\% (95\% CI: 10.0-15.8). Cognitive impairment was high in females (16.7\%, 95\% CI: 12.7-21.5) than in males $(7.6 \%, 95 \% \mathrm{CI}: 4.7-11.9)$, although there is significant sex differences $(P=0.0015)$. The overall prevalence of depression was $24.3 \%$ (95\% CI: 20.8-28.3). Depression was slightly higher in females $(25.3 \%)$ than in males $(23.1 \%)$, although there is no significant sex differences $(P=0.55)$.

\section{Correlates of cognitive impairment and depression}

Table 3 presents univariate comparison of cognitive impairment with sociodemographic data and depression. In univariate analysis, cognitive impairment is associated with female sex $(\mathrm{OR}=0.40,95 \% \mathrm{CI}: 0.23-0.72)$, being not married ( single/divorced/widowed; OR $=2.67,95 \%$ CI: $1.58-4.51$ ), being older than 75 years (OR $=0.15,95 \% \mathrm{CI}$ : 0.08-0.28), low level of education ( $\mathrm{OR}=5.58,95 \% \mathrm{CI}: 3.26-9.54)$, low monthly income $(\mathrm{OR}=1.74,95 \% \mathrm{CI}: 1.0-3.03)$, and depression (OR $=3.33$, 95\% CI: 1.97-5.63). Similarly, in adjusted analysis, the following factors were independent predictors of cognitive impairment in our sample: female sex, low level of education, being older than 75 years, and depression.

Table 4 summarizes estimated crude and adjusted OR showing the association of depression with sociodemographic 
Table 2 Prevalence of cognitive impairment and depression by sex $(\mathrm{N}=538)$

\begin{tabular}{|c|c|c|c|c|c|c|}
\hline \multirow[t]{2}{*}{ Variables } & \multicolumn{3}{|c|}{ Cognitive impairment } & \multicolumn{3}{|l|}{ Depression } \\
\hline & Presence, n (\%) & $95 \% \mathrm{Cl}$ & Absence, n (\%) & Presence, n (\%) & $95 \% \mathrm{Cl}$ & Absence, n (\%) \\
\hline Male & $18(7.6)$ & $4.7-11.9$ & $220(92.4)$ & $55(23.1)$ & $18.0-29.1$ & $183(76.9)$ \\
\hline Female & $50(16.7)$ & $|2.7-2| .5$ & $250(83.3)$ & $76(25.3)$ & $20.6-30.7$ & $224(74.7)$ \\
\hline Total & $68(12.6)$ & $10.0-15.8$ & $470(87.4)$ & $|3|(24.3)$ & $20.8-28.3$ & $407(75.7)$ \\
\hline
\end{tabular}

Abbreviation: $\mathrm{Cl}$, confidence interval.

Table 3 Relationship between cognitive impairment, sociodemographic data, and depression ( $N=538)$

\begin{tabular}{|c|c|c|c|c|c|}
\hline \multirow[t]{2}{*}{ Variables } & \multicolumn{2}{|c|}{ Cognitive impairment } & \multirow[t]{2}{*}{ OR $(95 \% \mathrm{Cl})$} & \multirow{2}{*}{$\begin{array}{l}\text { *Adjusted } \\
\text { OR (95\% Cl) }\end{array}$} & \multirow[t]{2}{*}{$P$-value } \\
\hline & Yes, n (\%) & No, n (\%) & & & \\
\hline$\overline{\text { Sex }}$ & & & & & 0.046 \\
\hline Male & $18(7.6)$ & $220(92.4)$ & $0.40(0.23-0.72)^{*}$ & $0.50(0.26-0.98)^{*}$ & \\
\hline Female & $50(16.7)$ & $250(83.3)$ & 1 & & \\
\hline Marital status & & & & & 0.801 \\
\hline Single/widow/divorce & $3 \mid(2 \mid .7)$ & $112(78.3)$ & $2.67(I .58-4.5 I)^{*}$ & $1.08(0.58-2.02)$ & \\
\hline Married & $37(9.4)$ & $358(90.6)$ & I & & \\
\hline Education (years) & & & & & $<0.00$ I \\
\hline $0-5$ & $35(31.8)$ & $75(68.2)$ & $5.58(3.26-9.54)^{*}$ & $3.80(2.02-7.13)^{*}$ & \\
\hline$\geq 6$ & $33(7.7)$ & $395(92.3)$ & 1 & & \\
\hline Age (years) & & & & & $<0.00$ I \\
\hline$\leq 74$ & I5 (4.7) & $305(95.3)$ & $0.15(0.08-0.28)^{*}$ & $0.15(0.08-0.31)^{*}$ & \\
\hline$\geq 75$ & $53(24.3)$ & $165(75.7)$ & 1 & & \\
\hline Monthly income (RMB) & & & & & 0.138 \\
\hline$<3,000$ & $48(15)$ & $272(85)$ & $1.74(1.0-3.03)^{*}$ & $1.69(0.84-3.39)$ & \\
\hline$\geq 3,000$ & $20(9.2)$ & $198(90.8)$ & I & & \\
\hline Depression & & & & & $<0.00 \mathrm{I}$ \\
\hline Yes & $32(24.4)$ & $99(75.6)$ & $3.33(1.97-5.63)^{*}$ & $2.98(1.64-5.40)^{*}$ & \\
\hline No & $36(8.8)$ & 371 (9I.2) & I & & \\
\hline
\end{tabular}

Notes: OR adjusted by marital status, education, age, monthly income, and depression. $* P<0.05$.

Abbreviations: OR, odds ratio; $\mathrm{Cl}$, confidence interval; $\mathrm{RMB}$, Renminbi.

Table 4 Relation between depression, sociodemographic data, and cognitive impairment ( $N=538)$

\begin{tabular}{|c|c|c|c|c|c|}
\hline \multirow[t]{2}{*}{ Variables } & \multicolumn{2}{|l|}{ Depression } & \multirow[t]{2}{*}{ OR (95\% CI) } & \multirow{2}{*}{$\begin{array}{l}\text { *Adjusted } \\
\text { OR }(95 \% \mathrm{CI})\end{array}$} & \multirow[t]{2}{*}{$P$-value } \\
\hline & Yes, n (\%) & No, n (\%) & & & \\
\hline Sex & & & & & 0.943 \\
\hline Male & $55(23.1)$ & $183(76.9)$ & $0.88(0.59-1.31)$ & 1.01 (0.64-1.59) & \\
\hline Female & $76(25.3)$ & $224(74.7)$ & I & & \\
\hline Marital status & & & & & 0.083 \\
\hline Single/divorce/widow & $48(33.6)$ & $95(66.4)$ & 1.89 (1.24-2.90)* & $1.52(0.94-2.44)$ & \\
\hline Married & $83(2 I)$ & $312(79)$ & 1 & & \\
\hline Education (years) & & & & & 0.963 \\
\hline $0-5$ & $32(29.1)$ & $78(70.9)$ & $1.36(0.85-2.17)$ & $0.98(0.57-1.69)$ & \\
\hline$\geq 6$ & $99(23.1)$ & $329(76.9)$ & 1 & & \\
\hline Age (years) & & & & & 0.113 \\
\hline$\leq 74$ & $60(18.8)$ & $260(81.2)$ & $0.47(0.32-0.71)^{*}$ & $0.68(0.43-1.09)$ & \\
\hline$\geq 75$ & $71(32.6)$ & 147 (67.4) & 1 & & \\
\hline Monthly income (RMB) & & & & & 0.391 \\
\hline$<3,000$ & $73(22.8)$ & 247 (77.2) & $0.81(0.54-1.21)$ & $0.81(0.5|-| .29)$ & \\
\hline$\geq 3,000$ & $58(26.6)$ & $160(73.4)$ & 1 & & \\
\hline Cognitive impairment & & & & & $<0.00$ I \\
\hline Yes & $32(47.1)$ & $36(52.9)$ & $3.33(1.97-5.63)^{*}$ & $2.74(1.52-4.94)^{*}$ & \\
\hline No & $99(21.1)$ & $37 \mid(78.9)$ & I & & \\
\hline
\end{tabular}

Notes: OR adjusted by marital status, education, age, monthly income, and cognitive impairment. $* P<0.05$.

Abbreviations: $\mathrm{OR}$, odds ratio; $\mathrm{Cl}$, confidence interval; $\mathrm{RMB}$, Renminbi. 
data and cognitive impairment. In univariate analysis, depression is significantly associated with being not married (single/ divorced/widowed; OR $=1.89$, 95\% CI: 1.24-2.90), older than 75 years $(\mathrm{OR}=0.47,95 \% \mathrm{CI}: 0.32-0.71)$, and cognitively impaired (OR $=3.33$, 95\% CI: 1.97-5.63). Similarly, in adjusted analysis, only cognitive impairment was an independent predictor of depression.

\section{Discussion}

Very few studies have ever been conducted on depression and cognitive impairment among elderly people in Chongqing, People's Republic of China. However, depression and cognitive impairment in older adults may have significant consequence for health care system in the People's Republic of China and many other developed countries. To the best of our knowledge, this is the first study describing the prevalence and correlates of cognitive impairment and depression in the elderly Chinese people in Chongqing.

\section{Prevalence of cognitive impairment}

We found that the prevalence of cognitive impairment was $12.6 \%$ among elderly Chongqing people, which was somewhat higher than that from Spanish representative sample $(9.6 \%)^{17}$ but lower than that from the Mayo Clinic study of aging (16.0\%). ${ }^{18}$ A study in our neighboring country, India, Lucknow, reported that the prevalence of cognitive impairment was $7.6 \% .{ }^{19}$ The prevalence studies of cognitive impairment in the US and Canada reveal relatively consistent findings. In the US and Canada, 22.2\% and $16.8 \%$, respectively, of elderly population have cognitive impairment without dementia. ${ }^{20,21}$ In different parts of the People's Republic of China, the prevalence of mild cognitive impairment ranges from $5.4 \%$ to $25 \% .^{22}$ Recent study conducted in urban community of the People's Republic of China reported that the prevalence of cognitive impairment was $20 \%,{ }^{23}$ while other studies reported $7 \%$ and $8.38 \%{ }^{11,24}$ In contrast, the cognitive impairment in community-dwelling elderly population in Turkey was $26.1 \%$ (20.6\% in males and $31.5 \%$ in females). ${ }^{25}$ The variation in the prevalence of cognitive impairment may be due to the differences in the characteristics of study samples, such as ages covered in the studies, diagnostic criteria, evaluation tools, education level, and lifestyles.

Being consistent with previous results, ${ }^{26,27}$ the results of the current study revealed that females had higher prevalence of cognitive impairment than males. In contrast, studies from developed countries have found no sex differences in the prevalence of cognitive impairment. ${ }^{28,29}$ Sex differences in cognitive impairment in the People's Republic of China may be due to the disparity in education level, usage of social cognitive skills, and sex inequalities.

Similar to other studies, ${ }^{9,30,31}$ the prevalence of cognitive impairment in this study increased with advanced age. Jorm and Jolley ${ }^{32}$ revealed that the prevalence of cognitive impairment doubles every 5.2 years, more or less in an exponential manner, between the ages of 65 years and 85 years.

Regarding marital status, we found that single/divorced/ widowed individuals were more likely to be cognitively impaired than married elderly individuals $(P<0.001)$. This is in agreement with previous studies, ${ }^{33,34}$ which found that single elderly individuals are at great risk of suffering dementia than married individuals. Marriage has protective benefits on cognitive function, which is in consistent with the results from the previous studies in $\mathrm{Asian}^{35}$ and Caucasian populations. ${ }^{36,37}$ The engagement of married individuals in more social and cognitive activities than single individuals can protect them from cognitive impairment.

Similar to our study, some studies ${ }^{33,38,39}$ have shown that the lower educational level was associated with increased cognitive impairment. However, some studies have revealed that education level does not have a protective effect against cognitive impairment. ${ }^{40,41}$

Similar to previous evidence, our study also indicated that the presence of depression is associated with an increased risk of cognitive impairment. ${ }^{42,43}$ After adjusting for sociodemographic factors, we found an independent association between depression and cognitive impairment. In Mexican Americans, the presence of depressive symptoms was associated with subsequent cognitive impairment. ${ }^{44}$ Hence, early detection of depressive symptoms in elderly people with cognitive impairment is a cornerstone to develop preventive and early rehabilitation.

\section{Prevalence of depression}

The overall prevalence of depression in elderly Chinese people was found to be $24.3 \%$ (95\% CI: $20.8 \%-28.3 \%$ ), which is similar to the finding of meta-analysis of the 81 published articles on depressive symptoms in older Chinese adults. ${ }^{45}$ This finding was much higher than the previous reported figures. ${ }^{46,47}$ The prevalence of depression was $13.2 \% .^{48}$ in elderly Mexico Hispanic people and 40\% in hospitalized and nursing home elderly people. ${ }^{49}$ The recent study by $\mathrm{Yu}$ et $\mathrm{al}^{50}$ revealed that the overall prevalence rate of depressive symptoms in older Chinese adults was $39.86 \%$. Thus, in the past few years, there is a gradual increment in the prevalence of depressive symptoms in older Chinese adults. The regional 
discrepancy in economic development, labor migration, culture, and lifestyles might be the cause for regional variation in the prevalence of depressive symptoms. With rapid industrialization and urbanization, socioeconomic transition has lead to weakening of Chinese family values, family social support, and spiritual comfort for older adults, which may be the reason for increased prevalence of depression.

In the present study, we found that marital status, increasing age, and cognitive impairment were associated with high risk of late-life depression. Similar findings have been reported among the geriatric population in Pakistan ${ }^{51}$ and India. ${ }^{52}$ Some studies have shown that marital status is a risk factor for depression in the elderly population, ${ }^{53-55}$ whereas, some studies have opposite opinion. ${ }^{56,57}$ In line with the findings of Yan et al, ${ }^{58}$ our findings suggest that marital status is a significant predictor of depressive symptoms in the older Chinese population. Specifically, single/divorced/ elderly individuals are more likely to have higher depressive symptoms than married individuals. The reason for this may be unmarried elderly people might experience more loneliness, poorer social support, lower self-confidence and are more likely to be living alone. However, when all covariates were controlled for, marital status lost its effect on depressive symptoms.

Similar to other studies, ${ }^{59,60}$ in our study, we encounter a higher prevalence of depressive symptoms with increasing age only in univariate analysis. However, inconsistent with previous studies, ${ }^{3,47}$ when all covariates were controlled for, age lost its effect on depressive symptoms. According to Blazer and Williams, ${ }^{61}$ the difference in rates of depression in old-aged females and males is progressively smaller and may disappear among members of older age groups. It might be due to relative decrease of depression in postmenopausal females. Cognitively impaired elderly individual has been prone to exhibit increased risk of depression. ${ }^{42}$ Consistent with other studies, 6,62 in our study, cognitive impairment was the most consistent factor, being associated with depression in both univariate and multivariate analyses. According to Wilson et al, ${ }^{63}$ depression represents an independent risk factor for cognitive impairment. The cognitively impaired individuals were found to be more than two times at risk of depression in the present study. Depression is linked to cognitive impairment, and elderly people with cognitive impairment exhibit increased risk of depression. ${ }^{64,65}$

\section{Study limitation}

There were few potential limitations in our study. First, it was a cross-sectional study performed in Chongqing, People's Republic of China, where economic development, labor migration, culture, and lifestyles may influence the prevalence of cognitive impairment and depression. Second, the significant associations found here do not suggest directional causation. Further research, using a longitudinal design, is recommended in order to investigate the detailed causal relationship between cognitive impairment and late-life depression.

Although the tools used to measure cognitive impairment and depression have been validated in Chinese population, they are screening tools, and a measurement bias due to actual disease status cannot be ignored. Despite these limitations, our study has several strengths. We investigated the factors linked to cognitive impairment and depression in older adults in Chongqing, which have been rarely studied despite their clinical importance. The study will be very important for guiding early interventions to prevent progression of MCI to dementia and potentially decrease depression among elderly people.

\section{Conclusion}

Our study provides useful information on the prevalence of cognitive impairment and depression among older adults and its correlates in Chongqing, People's Republic of China. The study confirms the linkage between depression and impaired cognitive functioning in a Chinese population. The relation between depression and cognition is very complex. It is very difficult to conclude where cognitive impairment begins and where depression ends or vice versa. In the elderly population, both cognitive impairment and depression have become public health problems.

\section{Acknowledgments}

This study was supported by grants from National Key Clinical Specialties Construction Program of China (no [2013]544), Application Program of Chongqing Science \& Technology Commission (cstc2014yykfA110002), Subproject under Science and Technology Program for Public Wellbeing of Chongqing Science \& Technology Commission (cstc2015jcsf10001-01-01), and Sub-project of National Science and Technology Supporting Program of the Ministry of Science and Technology of China (2015BAI06B04).

\section{Disclosure}

The authors report no conflicts of interest in this work.

\section{References}

1. Chen Z, Yu J, Song Y, Chui D. Aging Beijing: challenges and strategies of health care for the elderly. Ageing Res Rev. 2010;9(suppl 1):S2-S5.

2. Dening T, Barapatre C. Mental health and the ageing population. $J \mathrm{Br}$ Menopause Soc. 2004;10:49-53,64. 
3. Blazer DG. Depression in late life: review and commentary. J Gerontol A Biol Sci Med Sci. 2003;58(3):249-265.

4. Lebowitz BD, Pearson JL, Schneider LS, et al. Diagnosis and treatment of depression in late life. Consensus statement update. JAMA 1997;278(14):1186-1190.

5. Teresi J, Abrams R, Holmes D, Ramirez M, Eimicke J. Prevalence of depression and depression recognition in nursing homes. Soc Psychiatry Psychiatr Epidemiol. 2001;36(12):613-620.

6. Gao S, Jin Y, Unverzagt FW, et al. Correlates of depressive symptoms in rural elderly Chinese. Int J Geriatr Psychiatry. 2009;24(12): 1358-1366.

7. Lai DW. Depression among elderly Chinese-Canadian immigrants from Mainland China. Chin Med J (Engl). 2004;117(5):677-683.

8. Ma X, Xiang YT, Li SR, et al. Prevalence and sociodemographic correlates of depression in an elderly population living with family members in Beijing, China. Psychol Med. 2008;38(12):1723-1730.

9. Rait G, Fletcher A, Smeeth L, et al. Prevalence of cognitive impairment: results from the MRC trial of assessment and management of older people in the community. Age Ageing. 2005;34(3):242-248.

10. Nie H, Xu Y, Liu B, et al. The prevalence of mild cognitive impairment about elderly population in China: a meta-analysis. Int $J$ Geriatr Psychiatry. 2011;26(6):558-563.

11. Yao YH, Xu RF, Tang HD, et al. Cognitive impairment and associated factors among the elderly in the Shanghai suburb: findings from a loweducation population. Neuroepidemiology. 2010;34(4):245-252.

12. Liu M, He Y, Jiang B, et al. Association between metabolic syndrome and mild cognitive impairment and its age difference in a Chinese community elderly population. Clin Endocrinol (Oxf). 2015;82(6): 844-853.

13. Yesavage JA, Brink TL, Rose TL, et al. Development and validation of a geriatric depression screening scale: a preliminary report. $J$ Psychiatr Res. 1983;17(1):37-49.

14. Chan AC. Clinical validation of the Geriatric Depression Scale (GDS): Chinese version. J Aging Health. 1996;8(2):238-253.

15. Folstein MF, Folstein SE, McHugh PR. "Mini-mental state". A practical method for grading the cognitive state of patients for the clinician. J Psychiatr Res. 1975;12(3):189-198.

16. Petersen RC. Mild cognitive impairment as a diagnostic entity. J Intern Med. 2004;256(3):183-194.

17. Lara E, Koyanagi A, Olaya B, et al. Mild cognitive impairment in a Spanish representative sample: prevalence and associated factors. Int $J$ Geriatr Psychiatry. Epub 2016 Feb 28.

18. Petersen RC, Roberts RO, Knopman DS, et al. Prevalence of mild cognitive impairment is higher in men. The Mayo Clinic Study of Aging. Neurology. 2010;75(10):889-897.

19. Tiwari SC, Tripathi RK, Kumar A, et al. Prevalence of psychiatric morbidity among urban elderlies: Lucknow elderly study. Indian J Psychiatry. 2014;56(2):154-160.

20. Plassman BL, Langa KM, Fisher GG, et al. Prevalence of cognitive impairment without dementia in the United States. Ann Intern Med. 2008;148(6):427-434.

21. Graham JE, Rockwood K, Beattie BL, et al. Prevalence and severity of cognitive impairment with and without dementia in an elderly population. Lancet. 1997;349(9068):1793-1796.

22. Cheng Y, Xiao S. Recent research about mild cognitive impairment in China. Shanghai Arch Psychiatry. 2014;26(1):4-14.

23. Ding D, Zhao Q, Guo Q, et al. Prevalence of mild cognitive impairment in an urban community in china: a cross-sectional analysis of the Shanghai Aging Study. Alzheimers Dement. 2015;11(3):300-309.e2.

24. Zhuang JP, Wang G, Cheng Q, et al. Cognitive impairment and the associated risk factors among the elderly in the Shanghai urban area: a pilot study from China. Transl Neurodegener. 2012;1(1):22.

25. Arguvanli S, Akin S, Deniz Safak E, et al. Prevalence of cognitive impairment and related risk factors in community-dwelling elderly in Kayseri, Turkey. Turk J Med Sci. 2015;45(5):1167-1172.

26. Yu ES, Liu WT, Levy P, et al. Cognitive impairment among elderly adults in Shanghai, China. J Gerontol. 1989;44(3):S97-S106.
27. Ho SC, Woo J, Sham A, Chan SG, Yu AL. A 3-year follow-up study of social, lifestyle and health predictors of cognitive impairment in a Chinese older cohort. Int J Epidemiol. 2001;30(6):1389-1396.

28. Chodosh J, Reuben DB, Albert MS, Seeman TE. Predicting cognitive impairment in high-functioning community-dwelling older persons: Macarthur studies of successful aging. J Am Geriatr Soc. 2002;50(6): 1051-1060.

29. Mielke MM, Vemuri P, Rocca WA. Clinical epidemiology of Alzheimer's disease: assessing sex and gender differences. Clin Epidemiol. 2014;6: $37-48$.

30. Huang RY, Tang MN, Ma C, et al. The prevalence of mild cognitive impairment of residents aged 60 years and over in the urban and rural areas in Guangzhou. Chin J Nerv Ment Dis. 2008;34:533-537.

31. Hardy JA, Higgins GA. Alzheimer's disease: the amyloid cascade hypothesis. Science. 1992;256:184-185.

32. Jorm AF, Jolley D. The incidence of dementia: a meta-analysis. Neurology. 1998;51(3):728-733.

33. Rodríguez-Sánchez E, Mora-Simón S, Patino-Alonso MC, et al. Prevalence of cognitive impairment in individuals aged over 65 in an urban area: DERIVA study. BMC Neurol. 2011;11:147.

34. Helmer C. Dementia and marital status at midlife and late life. $B M J$. 2009;339:b1690

35. Feng L, Ng XT, Yap P, et al. Marital status and cognitive impairment among community-dwelling Chinese older adults: the role of gender and social engagement. Dement Geriatr Cogn Dis Extra. 2014;4(3): 375-384.

36. Håkansson K, Rovio S, Helkala EL, et al. Association between midlife marital status and cognitive function in later life: population based cohort study. BMJ. 2009;339:b2462.

37. van Gelder BM, Tijhuis M, Kalmijn S, Giampaoli S, Nissinen A, Kromhout D. Marital status and living situation during a 5-year period are associated with a subsequent 10-year cognitive decline in older men: the FINE study. J Gerontol B Psychol Sci Soc Sci. 2006;61(4):213-219.

38. De Ronchi D, Palmer K, Pioggiosi P, et al. The combined effect of age, education, and stroke on dementia and cognitive impairment no dementia in the elderly. Dement Geriatr Cogn Disord. 2007;24(4):266-273.

39. Su X, Shang L, Xu Q, et al. Prevalence and predictors of mild cognitive impairment in Xi'an: a community-based study among the elders. PLoS One. 2014;9(1):e83217.

40. Anstey KJ, Burns RA, Birrell CL, Steel D, Kiely KM, Luszcz MA. Estimates of probable dementia prevalence from population-based surveys compared with dementia prevalence estimates based on metaanalyses. BMC Neurol. 2010;10:62.

41. Maruta C, Guerreiro M, de Mendonca A, Hort J, Scheltens P. The use of neuropsychological tests across Europe: the need for a consensus in the use of assessment tools for dementia. Eur J Neurol. 2011;18(2): $279-285$.

42. Steffens DC, Otey E, Alexopoulos GA, et al. Perspectives on depression, mild cognitive impairment and cognitive decline. Arch Gen Psychiatry. 2006;63(2):130-138.

43. Ganguli M, Du Y, Dodge HH, Ratcliff GG, Chang CC. Depressive symptoms and cognitive decline in late life: a prospective epidemiologic study. Arch Gen Psychiatry. 2006;14:419-427.

44. Raji MA, Reyes-Ortiz CA, Kuo YF, Markides KS, Ottenbacher KJ. Depressive symptoms and cognitive change in older Mexican Americans. J Geriatr Psychiatry Neurol. 2007;20(3):145-152.

45. Li D, Zhang DJ, Shao JJ, Qi XD, Tian L. A meta-analysis of the prevalence of depressive symptoms in Chinese older adults. Arch Gerontol Geriatr. 2014;58(1):1-9.

46. Chen R, Copeland JR, Wei L. A meta-analysis of epidemiological studies in depression of older people in the People's Republic of China. Int J Geriatr Psychiatry. 1999;14(10):821-830.

47. Li N, Pang L, Chen G, Song X, Zhang J, Zheng X. Risk factors for depression in older adults in Beijing. Can J Psychiatry. 2011;56(8): 466-473.

48. Romero LJ, Ortiz IE, Finley MR, Wayne S, Lindeman RD. Prevalence of depressive symptoms in new Mexico Hispanic and non-Hispanic white elderly. Ethn Dis. 2005;15(4):691-697. 
49. Leon FG, Ashton AK, D'Mello DA, et al. Depression and comorbid medical illness: therapeutic and diagnostic challenges. J Fam Pract. 2003;suppl:S19-S23.

50. Yu J, Li J, Cuijpers P, Wu S, Wu Z. Prevalence and correlates of depressive symptoms in Chinese older adults: a population-based study. Int $J$ Geriatr Psychiatry. 2012;27(3):305-312.

51. Taqui AM, Itrat A, Qidwai W, Qadri Z. Depression in the elderly: does family system play a role? A cross-sectional study. BMC Psychiatry. 2007; 7:57

52. Kamble SV, Dhumale GB, Goyal RC, Phalke DB, Ghodke YD. Depression among elderly persons in a primary health centre area in Ahmednagar, Maharashtra. Indian J Public Health. 2009;53(4):253-255.

53. Zisook S, Kendler KS. Is bereavement-related depression different than non-bereavement-related depression? Psychol Med. 2007;37(6): 779-794.

54. Prince MJ, Harwood RH, Blizard RA, Thomas A, Mann AH. Social support deficits, loneliness and life events as risk factors for depression in old age. The Gospel Oak Project VI. Psychol Med. 1997;27(2): 323-332.

55. McCall NT, Parks P, Smith K, Pope G, Griggs M. The prevalence of major depression or dysthymia among aged Medicare fee-for-service beneficiaries. Int J Geriatr Psychiatry. 2002;17(6):557-565.

56. Sewitch MJ, McCusker J, Dendukuri N, Yaffe MJ. Depression in frail elders: impact on family caregivers. Int J Geriatr Psychiatry. 2004;19(7): 655-665.

57. Phifer JF, Murrell SA. Etiologic factors in the onset of depressive symptoms in older adults. J Abnorm Psychol. 1986;95:282-291.
58. Yan XY, Huang SM, Huang CQ, Wu WH, Qin Y. Marital status and risk for late life depression: a meta-analysis of the published literature. J Int Med Res. 2011;39(4):1142-1154.

59. Chen S, Conwell Y, Vanorden K, et al. Prevalence and natural course of late-life depression in China primary care: a population based study from an urban community. J Affect Disord. 2012;141(1):86-93.

60. Bergdahl E, Gustavsson JM, Kallin K, et al. Depression among the oldest old: the Umea 85+ study. Int Psychogeriatr. 2005;17(4):557-575.

61. Blazer D, Williams CD. Epidemiology of dysphoria and depression in an elderly population. Am J Psychiatry. 1980;137(4):439-444.

62. Gibson RC, Neita SM, Abel WD, James K, Eldemire-Shearer D. Sociodemographic factors associated with depressive symptoms among elderly persons from two communities in Kingston, Jamaica. West Indian Med J. 2013;62(7):615-619.

63. Wilson RS, Mendes De Leon CF, Bennett DA, Bienias JL, Evans DA. Depressive symptoms and cognitive decline in a community population of older persons. J Neurol Neurosurg Psychiatry. 2004;75(1): 126-129.

64. Barnes DE, Alexopoulos GS, Lopez OL, Williamson JD, Yaffe K. Depressive symptoms, vascular disease, and mild cognitive impairment: findings from the cardiovascular health study. Arch Gen Psychiatry. 2006;63(3):273-279.

65. Modrego PJ, Ferrández J. Depression in patients with mild cognitive impairment increases the risk of developing dementia of Alzheimer type: a prospective cohort study. Arch Neurol. 2004;61(8):1290-1293.
Clinical Interventions in Aging

\section{Publish your work in this journal}

Clinical Interventions in Aging is an international, peer-reviewed journal focusing on evidence-based reports on the value or lack thereof of treatments intended to prevent or delay the onset of maladaptive correlates of aging in human beings. This journal is indexed on PubMed Central, MedLine,

\section{Dovepress}

CAS, Scopus and the Elsevier Bibliographic databases. The manuscript management system is completely online and includes a very quick and fair peer-review system, which is all easy to use. Visit http://www.dovepress. com/testimonials.php to read real quotes from published authors. 